\title{
Territory quality and territorial behavior in two sympatric species of hummingbirds
}

\author{
Paul W. Ewald ${ }^{1}$ and Raymond J. Bransfield ${ }^{2 *}$ \\ ${ }^{1}$ Department of Biology, Amherst College, Amherst, MA 01002, USA, and \\ Museum of Zoology, Division of Biology and Michigan Society of Fellows, University of Michigan, \\ Ann Arbor, MI 48109, USA \\ ${ }^{2}$ Department of Biology, California State University, Long Beach, CA 90040, USA \\ Received July 14, 1986 / Accepted January 10, 1987
}

Summary. Changes in territorial behavior of blackchinned hummingbirds (Archilochus alexandri) in response to experimental changes in territory quality were investigated using artificial feeders and simultaneous, pair-wise observations of owners. Some of the responses of $A$. alexandri were similar to those documented by a previous study of the Anna's hummingbird (Calypte anna): $A$. alexandri defending rich territories spent more time on their territories, encountered a greater percentage of intruders, and chased more intruders than $\operatorname{did} A$. alexandri defending poor territories. In contrast to $C$. anna, $A$. alexandri supplemented chases with energetically inexpensive threat vocalizations more extensively when territory quality was increased. This difference may be related to $A$. alexandri's more tenuous control of rich territories. When both species were observed on very poor territories, $A$. alexandri chased a greater percentage of intruders, consumed a greater proportion of available food, and obtained a greater net energy gain from their territories. When observed simultaneously on territories with ad lib food, both species defended highly exclusive territories but $A$. alexan$d r i$ suffered higher intrusion pressure and spent more time and energy in defense. These interspecific differences in territorial behavior may facilitate sympatric coexistence of the two species through aggressive partitioning of flower patches according to productivity: the greater payoff received by $C$. anna on rich territories and $A$. alexandri on poor territories should favor a corresponding monopolization of rich areas by $C$. anna and poor areas by $A$. alexandri.

\footnotetext{
* Present address: U.S. Fish and Wildlife Service, 24000 Avila Road, Laguna Niguel, CA 92677, USA

Offprint requests to: P.W. Ewald, Department of Biology, Amherst College, Amherst, MA 01002, USA
}

\section{Introduction}

During the last two decades the cost-benefit perspective has become the primary basis for understanding territorial behavior. One area in which this perspective has provided insight involves relationships between territory quality and the form of territorial defense. When territory quality decreases defenders may switch to less expensive forms of defense because the energetic savings outweigh greater loss of resources associated with such defenses (Ewald and Carpenter 1978).

Nectarivorous birds have been the primary subjects for investigations of these relationships because both territorial behavior and energetic costs and benefits are readily quantifiable, manipulable and relevant to fitness (Ewald 1985). These investigations show that under both experimental and unperturbed conditions and during both breeding and nonbreeding seasons, defenders alter methods of defense as territory quality changes (Stiles 1973, p. 53; Ewald and Carpenter 1978; Gass 1978; Frost and Frost 1980; Gass and Montgomerie 1981; Wilhelm et al. 1980; Ewald and Orians 1983; Paton and Carpenter 1984; Tamm 1985; Armstrong 1987; Powers 1987).

The present study attempts to determine whether territorial responses to territory quality are related to interspecific dominance relationships between two sympatric nectarivores: the Anna's and black-chinned hummingbirds (Calypte anna and Archilochus alexandri). In the first part of this study we investigate effects of experimental changes in territory quality on the territorial behavior of $A$. alexandri. Because $A$. alexandri is generally subordinate to $C$. anna (Stiles 1973) it may not be able to invoke the same kinds of territorial responses that have been documented for $C$. anna (Ewald and Carpenter 1978; Ewald and Orians 
1983); for example, if $A$. alexandri attempted to reduce its defense expenditures it might become more vulnerable than $C$. anna to displacement.

In the second part of this study we compared the behavior of $A$. alexandri and $C$. anna when each species defended territories of equal quality. Interspecific differences in energy requirements might lead to agonistic control of poor resources by $A$. alexandri and rich resources by $C$. anna. The logic underlying this expectation derives from the existing theoretical framework for intraspecific dominance (Parker 1974; Maynard Smith and Parker 1976; for the definition of dominance adhered to in the present paper see Ewald 1985). This framework proposes that the motivation to fight an adversary, and hence the outcome of fights, should depend on differences between contestents in expected payoffs from victory (termed "payoff asymmetries" by Maynard Smith and Parker 1976).

Rates of total energy expenditure per bird are greater for $C$. anna than for the smaller $A$. alexandri (Lasiewski 1963; Epting 1980; Ewald and Rohwer 1980); hence, on poor territories $A$. alexandri would receive a greater proportion of its energy requirement. $A$. alexandri's fitness payoff on poor territories should, therefore, tend to be greater than $C$. anna's, and $A$. alexandri should be more motivated to fight for control of such poor territories. In this case the payoff is the increased probability of survival that results from ownership of the resource. Because investment in territorial defense declines gradually as territory productivity falls below an owners energetic requirements (Ewald and Carpenter 1978), we expected that $A$. alexandri would defend poor but not rich areas more intensely than $C$. anna. The present study tests this prediction by quantifying investments in and payoffs from territorial defense for these two species on both poor and rich territories.

\section{Methods}

\section{Study population and area}

Observations of $A$. alexandri's territorial responses to changes in territory quality were conducted from 30 July through $29 \mathrm{Au}-$ gust 1980, and 9 July through 24 August 1981, at Starr Ranch National Audubon Sanctuary, Santa Ana Mountains, Orange County, California. Simultaneous comparisons of $A$. alexandri with $C$. anna on poor territories were made from 16 August through 31 August 1982 at Hastings Natural History Reserve of the University of California, Santa Lucia Mountains, Monterey County, California. Interspecific comparisons on rich territories were made from 14-26 August 1977 at Tucker Wildlife Sanctuary, Santa Ana Mountains, Orange County, California.
Observations were made in riparian woodland predominated by coast live oak (Quercus agrifolia). California fuchsia (Zauschneria californica) was the only flower regularly visited by hummingbirds at the Hastings site during the study period. Z. californica, scarlet monkey-flower (Mimulus cardinalis), bush monkey-flower (Mimulus longiflorus), and tree tobacco (Nicotiana glauca) bloomed sparsely at Starr and Tucker. Nectar available from these flowers yielded much less than $1 \%$ of the energy requirements of the hummingbird populations.

Approximately 150 hummingbirds were maintained at each study site by providing 50 feeders, each of which supplied $20 \%$ sucrose solution (containing red food coloring) ad lib. At the beginning of the study periods the abundances of $A$. alexandri and $C$. anna were approximately the same at both Hastings and Tucker. Approximately $90 \%$ of the population at Starr were $A$. alexandri. At all study sites the proportion of $C$. anna increased steadily during August when $A$. alexandri began to emigrate and $C$. anna continued to immigrate. By the beginning of September the vast majority of all birds were $C$. anna. Birds were marked with mixtures of vegetable oil and dyes (Rhodamine B, Oramine OO, Victoria green WB; see Ewald and Rohwer 1980).

Syringe pumps continuously delivered $20 \%$ sucrose solution to the rate-restricted feeders, which were constructed by decapitating $3 \mathrm{ml}$ syringes at the $1 \mathrm{ml}$ mark (Ewald 1985). To keep out insects, the open end was constricted to approximately $5 \mathrm{~mm}$ using silicone sealant, which was painted red to facilitate discovery by the birds.

All birds should have been able to satisfy their daily energy requirements. At Starr, food was available ad lib from feeders that were rendered undefendable by placing them in areas devoid of perches suitable for defense. At Hastings and Tucker, birds could obtain their energy requirements by spending about two hours per day intruding on territories containing ad lib feeders.

\section{Defense of $0.6,0.8$, and $1.0 \mathrm{ml} / \mathrm{h}$ feeders by $\mathrm{A}$. alexandri}

To establish territories, feeders providing $20 \%$ sucrose solution ad lib were spaced at approximately $10 \mathrm{~m}$ intervals. When territories were established on two neighboring feeders, each was replaced with a rate-restricted feeder. No other sources of nectar-type food were available on any territory. Both feeders of each pair were located in the same kind of vegetation to reduce effects of differences in microhabitat.

In the first set of experiments 10 pairs were provided sucrose solution at a rate of $0.8 \mathrm{ml} / \mathrm{h}$ (which provides approximately 1.7 times the $24 \mathrm{~h}$ energy expenditures of $A$. alexandri) for one bird and $0.6 \mathrm{ml} / \mathrm{h}$ for the other. In the second set, each of 10 pairs was provided with 0.8 and $1.0 \mathrm{ml} / \mathrm{h}$. The average amount of food assimilated by owners of $0.6 \mathrm{ml} / \mathrm{h}$ territories on their territories was approximately 0.9 times their daily energy expenditures, while the analogous factors for $0.8 \mathrm{ml} / \mathrm{h}$ and $1.0 \mathrm{ml} / \mathrm{h}$ territories were 1.3 and 1.8 (for details about energetic estimates, see Ewald 1985). Both birds in each pair were observed simultaneously for a 2 -h period with at least one observer per bird.

Birds that intruded on a territory in the presence of the owner were categorized as "encountered" except when an owner's vision of intruders was obstructed. "Chases" included any interaction in which an owner flew at an intruder in response to the intruder.

\section{Comparison of A. alexandri with C. anna}

For comparisons of $A$. alexandri with $C$. anna on poor territories $20 \%$ sucrose solution was provided from a single feeder 
at $0.3 \mathrm{ml} / \mathrm{h}$, yielding approximately 0.7 and 0.5 of the daily energy expenditures of $A$. alexandri and $C$. anna respectively. Triplets of regulated feeders were set in place a day before observations were first made to allow territory establishment. Each triplet was observed simultaneously by three observers for a two-hour period beginning at approximately $08: 00$ or 10:00 hours. A total of 6 different $A$. alexandri and 23 different $C$. anna were observed on their territories. The lower proportion of $A$. alexandri reflected their lower proportion in the population at this time of year.

To compare territoriality of $C$. anna and $A$. alexandri on extremely rich territories, feeders providing $20 \%$ sucrose solution ad lib were placed in riparian vegetation at intervals of approximately five $\mathrm{m}$. After adult male $C$. anna and $A$. alexan$d r i$ had defended adjacent feeders for at least one day, they were observed simultaneously for a 90 -min period by two observers.

To compare rates of food consumption by the two species, rates of weight gain per unit time licking at feeders were measured using the technique described by Ewald and Rohwer (1980) or a slight modification of that technique in which the feeder and weighing apparatus were suspended from a wooden structure (to prevent disturbances from breezes), which was suspended from tree branches using twine. Birds were weighed from 18-25 December 1977, 29 August-12 September 1979, and 9 July-23 August 1981.

\section{Statistical analysis}

Matched-pairs randomization tests (Siegel 1956) were used on data derived from pairwise observations of rich and poor owners and for pairwise observations of $A$. alexandri and $C$. anna.
Territories providing $0.8 \mathrm{ml} / \mathrm{h}$ were used as controls to compare the behavior of territory owners receiving $0.6 \mathrm{ml} / \mathrm{h}$ with those receiving $1.0 \mathrm{ml} / \mathrm{h}$. Each value obtained from the $0.8 \mathrm{ml} / \mathrm{h}$ territories was subtracted from the value obtained from the other territory $(0.6$ or $1.0 \mathrm{ml} / \mathrm{h})$ in that matched pair. The two samples derived from these subtractions were analyzed using a Mann-Whitney $U$-test. This procedure permitted comparisons over a greater range of energy availability. When the direction of the relationship between a behavioral variable and energy availability was the same for both sets of energy availability, the significance of the overall trend was examined using a combined probability test (Sokal and Rohlf 1981). When variables used in pair-wise comparisons met requirements for parametric tests paired $t$-tests were used rather than randomization tests.

Because $0.3 \mathrm{ml} / \mathrm{h}$ feeders provided a greater proportion of energy requirements for $A$. alexandri than for $C$. anna (i.e., as a consequence of the differences in body size), we expected $A$. alexandri to defend these feeders more intensely. One-tailed tests were therefore used for the corresponding comparisons unless otherwise indicated.

\section{Results}

Defense of 0.6, 0.8 , and $1.0 \mathrm{ml} / \mathrm{h}$ feeders by Archilochus alexandri

Owners of richer territories did not chase a greater percentage of encountered intruders (row 8 , Table 1), but did spend more time on their territories; the difference between $0.6 \mathrm{ml} / \mathrm{h}$ and 0.8 birds was

Table 1. Territoriality of $A$. alexandri at different rates of food provisioning. Matched-pairs randomization tests were used to compare 0.6 with $0.8 \mathrm{ml} / \mathrm{h}$ territories. Combined probability tests were used for testing the significance of overall trends when the trends over these two intervals were in the same direction. Mann-Whitney $U$-tests were used to compare 1.0 with $0.6 \mathrm{ml} / \mathrm{h}$ territories (see Methods). NA = combined probability test not applicable because trends associated with the two randomization tests were in opposite directions

\begin{tabular}{|c|c|c|c|c|c|c|c|c|}
\hline & \multicolumn{2}{|c|}{$\begin{array}{l}\text { Flow rates } \\
(\mathrm{ml} / \mathrm{h})\end{array}$} & \multirow[t]{2}{*}{$P$} & \multicolumn{2}{|c|}{$\begin{array}{l}\text { Flow rates } \\
(\mathrm{ml} / \mathrm{h})\end{array}$} & \multirow[t]{2}{*}{$P$} & \multirow[t]{2}{*}{ Combined $P$} & \multirow[t]{2}{*}{$1.0 \mathrm{vs} 0.6 P$} \\
\hline & 0.6 & 0.8 & & 0.8 & 1.0 & & & \\
\hline 1 Time on territory $(\%)$ & 63.9 & 86.8 & 0.004 & 73.0 & 89.5 & 0.06 & 0.001 & 0.001 \\
\hline 2 Production consumed $(\%)$ & 73.3 & 83.3 & $0.20 *$ & 74.6 & 89.1 & $0.19^{*}$ & $0.1<P<0.2 *$ & $0.06^{*}$ \\
\hline 3 Intruders encountered $(\%)$ & 77.4 & 93.7 & $<0.05$ & 83.3 & 98.1 & $<0.05$ & $<0.005$ & $<0.001$ \\
\hline $\begin{array}{l}4 \text { Encountered intruders/ } \\
\min ^{* *}\end{array}$ & 0.60 & 0.72 & 0.06 & 0.38 & 0.43 & 0.25 & $<0.05$ & $0.05<P<0.1$ \\
\hline 5 Time spent chasing $(\%)^{\mathrm{a}}$ & 2.5 & 4.9 & 0.11 & 2.2 & 2.9 & 0.09 & 0.01 & $<0.02$ \\
\hline 6 Seconds/chase & 4.7 & 5.2 & 0.06 & 4.7 & 4.4 & 0.45 & 0.11 & 0.34 \\
\hline 7 Intruders chased $(\%)$ & 71.8 & 89.8 & 0.05 & 82.1 & 92.6 & 0.05 & $<0.005$ & 0.02 \\
\hline $\begin{array}{l}8 \text { Encountered intruders } \\
\text { chased }(\%)\end{array}$ & 91.6 & 95.8 & 0.21 & 98.5 & 94.7 & 0.36 & NA & 0.40 \\
\hline $\begin{array}{l}9 \text { Intruders receiving chatter } \\
\text { without chase }(\%)\end{array}$ & 4.4 & 5.5 & 0.78 & 0.3 & 5.3 & $0.05<P<0.1$ & $>0.2$ & 0.18 \\
\hline 10 Chase: chatter ratio & 1.2 & 1.3 & 0.92 & 1.6 & 1.0 & 0.01 & NA & $0.12 *$ \\
\hline
\end{tabular}

* 2-tailed test

${ }^{a}$ Measured relative to time that owners were present on their territories 
Table 2. Territoriality of $A$. alexandri and $C$. anna when food was provisioned at $0.3 \mathrm{ml} / \mathrm{h}$. Randomization tests were used for paired comparisons and Mann-Whitney $U$-tests for comparisons of all 26 birds

\begin{tabular}{|c|c|c|c|c|c|c|}
\hline & \multicolumn{3}{|c|}{ Paired comparisons } & \multicolumn{3}{|l|}{ All birds } \\
\hline & A. alexandri & C.anna & $P$ & A. alexandri & C. anna & $P$ \\
\hline 1 Time on territory $(\%)$ & 61.8 & 26.4 & 0.03 & 56.8 & 31.4 & $<0.05$ \\
\hline 2 Production consumed (\%) & 76.4 & 33.1 & 0.03 & 74.1 & 43.1 & $<0.003$ \\
\hline 3 Intruders encountered $(\%)$ & 68.7 & 25.3 & 0.03 & 68.5 & 36.8 & $<0.01$ \\
\hline 4 Encountered intruders $/ \mathrm{min}^{\mathrm{a}}$ & 0.33 & 0.44 & $0.88 *$ & 0.36 & 0.37 & $>0.1$ \\
\hline 5 Time spent chasing $(\%)^{a}$ & 3.1 & 2.2 & $0.25 *$ & 3.5 & 2.5 & $0.08 *$ \\
\hline 6 Seconds/chase & 5.4 & 3.4 & $* *$ & 5.6 & 5.0 & 0.2 \\
\hline 7 Total intruders chased $(\%)$ & 65.9 & 23.1 & 0.03 & 66.2 & 35.4 & 0.02 \\
\hline 8 Encountered intruders chased $(\%)$ & 97.8 & 88.4 & $* *$ & 95.8 & 85.5 & $<0.05$ \\
\hline $\begin{array}{l}9 \text { Intruders receiving } \\
\text { chatter without chase }(\%)\end{array}$ & 0.0 & 4.5 & $* *$ & 1.3 & 12.2 & $<0.05$ \\
\hline 10 Chase: chatter ratio & 2.3 & 0.9 & $* *$ & 2.2 & 1.2 & 0.003 \\
\hline
\end{tabular}

significant, but that between $0.8 \mathrm{ml} / \mathrm{h}$ and $1.0 \mathrm{ml} / \mathrm{h}$ birds was marginal (row 1, Table 1). The trends over the entire range of energy availability were, however, highly significant (last two columns of row 1, Table 1). Owners of the richer territories chased significantly greater percentages of all intruders in both the $0.6 \mathrm{vs} .0 .8 \mathrm{ml} / \mathrm{h}$ and the $0.8 \mathrm{vs}$. $1.0 \mathrm{ml} / \mathrm{h}$ comparisons (row 7, Table 1), a consequence of the greater percentage of intruders encountered on richer territories (row 3 of Table 1).

Owners of richer territories consumed greater percentages of the food production in both sets of comparisons, but neither of these differences was statistically significant (row 2 , Table 1 ). When the percentage of production consumed at $0.6 \mathrm{ml} / \mathrm{h}$ was compared with that at $1.0 \mathrm{ml} / \mathrm{h}$, using the $0.8 \mathrm{ml} / \mathrm{h}$ feeders as controls (see Methods), the lower percentage of production consumed from $0.6 \mathrm{ml} / \mathrm{h}$ territories fell just short of statistical significance (last column of row 2, Table 1).

Owners of $1.0 \mathrm{ml} / \mathrm{h}$ feeders spent a significantly greater percentage of time chasing than owners of $0.6 \mathrm{ml} / \mathrm{h}$ feeders, but chasing times were not significantly different for the $0.6 \mathrm{vs} .0 .8 \mathrm{ml} / \mathrm{h}$ comparison or for the $0.8 \mathrm{vs} .1 .0 \mathrm{ml} / \mathrm{h}$ comparison (row 5 of Table 1). The mean duration of individual chases was not significantly different in any of these comparisons (row 6 of Table 1).

Hummingbirds occasionally chatter at rather than chase intruders. In contrast to the territorial responses of $C$. anna (see Ewald and Carpenter 1978), A. alexandri's use of chatter without chases was not greater on poorer territories (row 9, Table 1).

The ratio of number of chases to number of chatters reflects the use of an energetically expensive defense behavior relative to an inexpensive defense. This ratio was not significantly different in the $0.6 \mathrm{vs} 0.8 \mathrm{ml} / \mathrm{h}$ comparison, but owners of $1.0 \mathrm{ml} / \mathrm{h}$ feeders had a significantly lower ratio than owners of $0.8 \mathrm{ml} / \mathrm{h}$ feeders (row 10 of $\mathrm{Ta}$ ble 1). A greater frequency of chatters without chases on 1.0 relative to $0.8 \mathrm{ml} / \mathrm{h}$ territories (row 9 in Table 1) contributed to this trend. To determine whether owners of $1.0 \mathrm{ml} / \mathrm{h}$ territories also supplemented their chases with chatters more frequently than owners of $0.8 \mathrm{ml} / \mathrm{h}$ territories, we calculated a chase: chatter ratio using only chatters that accompanied chases. These ratios, 0.9 vs 1.6 for 1.0 vs $0.8 \mathrm{ml} / \mathrm{h}$ territories, respectively $(P<0.02$, 2 -tailed randomization test), confirm this supplementation hypothesis.

\section{Comparison of Archilochus alexandri with Calypte anna}

Interspecific dominance. In Stiles' (1973) observations of agonistic interactions between adult, male $C$. anna and $A$. alexandri at food sources not incorporated in territories, $C$. anna won $34(74 \%)$ of the 46 encounters for which victory was ascribed $(P=0.001$, binomial test, $z=3.1$ ).

Observations during 1981 and previous field seasons indicate that $C$. anna is also normally dom- 
inant to $A$. alexandri in disputes over ownership of rich territories. For territories providing 0.8 or more $\mathrm{ml} / \mathrm{h}$ we witnessed 5 takeovers of $A$. alexan$d r i$ 's territories by $C$. anna; however, the reciprocal takeover was never observed. The overall abundance of the two species was approximately equal during these takeovers. $C$. anna was more highly represented among territorial as opposed to nonterritorial individuals, but amounts of time spent observing territorial individuals were similar for the two species.

Poor territories. When each species defended $0.3 \mathrm{ml} / \mathrm{h}$ territories $A$. alexandri spent approximately twice as much time on their territories as C. anna, consumed approximately twice as much food, and encountered greater percentages of intruders (rows 1-3 of Table 2).

For one of the matched pairs two C. anna were paired with one $A$. alexandri. Each of these $C$. anna was compared individually with the $A$. alexandri. Although this procedure raises some uncertainty regarding independence of data points, a more conservative alternative of combining the two $C$. anna would fail to yield a test because a minimum of five pairs is needed. For each variable, however, the unpaired test yielded a significant difference in the same direction and of similar magnitude as the paired test (compare columns 1-3 with columns 4-6 in Table 2). We therefore conclude that the statistically significant differences are reliable.

$A$. alexandri chased a significantly greater percentage of all intruders and encountered intruders than did $C$. anna (rows 7 and 8, Table 2). In three of the 5 pairs, both members of the pair chased all encountered intruders. In each of the remaining pairs $A$. alexandri chased a greater percentage than did C. anna. No statistically significant differences existed between the species in the number of intruders encountered per minute on the territory in either the paired or the total samples (row 4, Table 2). Nor did A. alexandri and $C$. anna differ significantly in time spent chasing intruders (row 5 , Table 2).

Durations of chases by $A$. alexandri were not significantly longer than those by $C$. anna. Although the paired comparisons suggest a slight difference (row 6, Table 2) a randomization test could not be run on the data because only four paired comparisons were available; one bird chased only once during its paired observation period, and this chase was not accurately recorded. [To calculate percent time spent chasing intruders (row 5, Table 2) this chase was assigned the mean duration of the 47 chases $(3.8 \mathrm{~s})$ measured for this bird dur- ing three observation periods at the same time of day on the three successive days following the day of the paired observation]. When all birds are considered, the difference in chase duration is smaller than that of the paired comparisons and far from statistical significance (row 6, Table 2).

The preceding results show that $A$. alexandri defend poor territories more extensively than $C$. anna per unit of observation time (rows 1, 2 and 7 , Table 2), and with similar or more aggression while on the territory (rows 5, 6 and 8, Table 2). Do $A$. alexandri obtain a greater net energy gain from their territories? Such an asymmetry could make $A$. alexandri more motivated than $C$. anna to fight over territorial ownership of such poor resources (cf. Ewald 1985). To investigate this question we subtracted the estimated energy expenditure on the territory (including all perching, hovering and linear flight except for insect feeding) from the total amount of energy gained from the territory (i.e., energy consumed times a digestive efficiency of 0.98 ; Hainsworth 1974) for each observation period. Because the resultant data met the requirements for parametric statistics, we averaged the net energy gains of the two $C$. anna observed simultaneously with a single $A$. alexandri, and ran a paired t-test on the resultant four pairs. The average net energy gain was $554 \mathrm{~J} / \mathrm{h}$ for $A$. alexandri and $166 \mathrm{~J} / \mathrm{h}$ for $C$. anna (1-tailed $P<$ $0.005), t=5.32$ ).

C. anna chattered at unchased intruders more frequently than $A$. alexandri and had a lower chase: chatter ratio (rows 9 and 10, Table 2).

Territories providing food ad lib. Such interspecific differences were absent when the two species defended adjacent territories with ad lib sucrose solution. A. alexandri did not spend more time on their territories than $C$. anna (row 1, Table 3). Nor did they encounter a greater percentage of all intruders (row 2, Table $3 ; n=602$ and 968 intruders for $C$. anna and $A$. alexandri respectively). In three of the seven pairs both owners encountered $100 \%$ of the intruders; too few pairs (i.e., four) therefore remained to permit a matched-pairs randomization test. The two species did not differ significantly in the percentage of encountered intruders chased (row 7, Table 3).

In contrast to the absence of significant differences in intrusion pressure on poor territories, intrusion rates on rich territories defended by $A$. alexandri were 1.5 times that for $C$. anna (row 5 , Table 3). The two species did not differ significantly in the amount of time spent per chase (row 7, Table 3 ); consequently, A. alexandri spent more 
Table 3. Comparison of territorial behavior of $A$. alexandri with $C$. anna based on simultaneous pair-wise observations. Food was provided at ad lib on each territory. Data are based on 1490 -min periods on 14 different birds

\begin{tabular}{|c|c|c|c|}
\hline & A. alexandri & C. anna & $P * * *$ \\
\hline 1 Time on territory $(\%)$ & 97.0 & 99.5 & $0.25 *(\mathrm{R})$ \\
\hline 2 Intruders encountered $(\%)$ & 97.9 & 99.9 & $\mathrm{NA}^{* *}$ \\
\hline 3 Total intruders chased $(\%)$ & 96.8 & 99.2 & $\mathrm{NA}^{* *}$ \\
\hline 4 Encountered intruders chased $(\%)$ & 99.5 & 99.2 & $\mathrm{NA}^{* *}$ \\
\hline 5 Intruders per $\min ^{2}$ & 1.54 & 0.96 & $0.016(\mathrm{R})$ \\
\hline 6 Time chasing $(\%)^{a}$ & 11.6 & 7.4 & $<0.005(t)$ \\
\hline 7 Seconds/chase & 4.63 & 4.59 & $0.46(\mathrm{R})$ \\
\hline 8 Energy spent in defense (joules per min ${ }^{a}$ ) & 6.57 & 4.97 & $<0.02(t)$ \\
\hline 9 Time spent feeding (seconds per $\min ^{2}$ ) & 0.96 & 0.71 & $<0.025(t)$ \\
\hline
\end{tabular}

* 2-tailed

** Insufficient number of pairs for randomization test because both birds in several pairs had values of $100 \%$

$* * * \mathrm{R}=$ matched-pairs randomization test; $t$-values are from paired $t$-tests

a Measured relative to time that owners were present on their territories

time in chases than C. anna (row 6, Table 3). A parametric test was deemed appropriate for analyzing the difference in time spent chasing because both species spent similar amounts of time on their territories (row 1, Table 3); potential effects of this variable on the distribution of percentages of time spent chasing therefore seemed negligible.

Are $A$. alexandri spending more total energy in defense than $C$. anna on these rich territories? An asymmetry in defense costs could facilitate partitioning of the habitat according to food density by favoring $C$. anna in disputes over ownership of rich territories. Because C. anna are about $25 \%$ heavier than $A$. alexandri, the greater time expenditures by $A$. alexandri in defense do not necessarily correspond to greater energy expenditures. Note that it is the amount rather than the percentage of energy spent on defense that is relevant because the payoff from owning a territory is gain from defense minus the expenditure in defense (gains and expenditures being measured relative to the best alternative to territorial defense; see Wolf 1978).

We evaluated the preceding question in two ways. First we estimated energy spent in defense during the $90-\mathrm{min}$ observation periods using the methods described by Ewald (1985). According to these estimates, A. alexandri spent more energy (i.e., per bird per day) in territorial defense than C. anna (row 8, Table 3).

Differences in the energetic costs incurred by the two species may also be evaluated by comparing amounts of food consumed on their territories. Toward this end we calculated the amount of time that the two species spent feeding from their feeders. A. alexandri spent significantly more time feeding than $C$. anna (row 9, Table 3).
This difference in time spent feeding does not necessarily mean that $A$. alexandri consumed more food from the territory than $C$. anna because the extraction rates of the species may differ. To assess whether differences in food uptake rates offset differences in time spent feeding, the amount of food gained per second of feeding was estimated by measuring rates of weight gain by owners while they fed at unrestricted feeders (see "Comparison of $A$. alexandri with $C$. anna" in Methods). The mean rate at which $C$. anna extracted food from feeders while licking at the feeders $(0.0180 \mathrm{ml} / \mathrm{s}$, $n=14$ different birds) was not significantly different from that of $A$. alexandri $(0.0164 \mathrm{ml} / \mathrm{s}, n=39$ different birds; $0.3<P<0.4 ; t=0.88)$.

\section{Discussion}

\section{Territorial responses to energy availability in $A$. alexandri and $C$. anna}

The results show that $A$. alexandri altered their territorial behavior in response to changes in territory quality. Some of these responses are directly analogous to those documented for $C$. anna by Ewald and Carpenter (1978): decreases in territory quality resulted in decreases in the time spent on the territory, the percentage of total intruders encountered, and the percentage of intruders chased. In contrast to $C$. anna, percentages of time spent chasing, percentages of encountered intruders chased, and durations of chases were not lower on poorer territories.

The two species also differ in their relative use of chases and chatters. For C. anna, the chase: chatter ratio decreased as territory quality decreased, a change that resulted from a reduction 
in the use of chases. In the present study, the chase: chatter ratio for $A$. alexandri was lowest at $1.0 \mathrm{ml} /$ $\mathrm{h}$, the richest food level (row 10, Table 1). The lower chase: chatter ratio used against intruders chased from $1.0 \mathrm{ml} / \mathrm{h}$ territories confirms that chatter is used as a supplementation of chases.

Supplementary use of chatters at high levels of energy availability by $A$. alexandri but not by $C$. anna is explicable in terms of the generally subordinate social position of $A$. alexandri on rich territories. Reinforcement of their defense with chatters could communicate their identity as territory owners and/or their "determination" to defend their territories when the territories are attractive to $C$. anna. Interestingly, when territories were so poor that $C$. anna exhibited only weak defense (i.e., at $0.3 \mathrm{ml} / \mathrm{h}), A$. alexandri's use of chatter relative to chases is nearly half as frequent as at $0.6-1.0 \mathrm{ml} / \mathrm{h}$ (see Tables 1 and 2; $P=0.004$; 2-tailed MannWhitney $U$-test). In contrast, at such low levels of energy availability, chatters by $C$. anna, which are often sufficient to deter intruders, are used in place of chases, yielding savings of energy (see rows 7, 9, and 10 of Table 2 and Ewald and Carpenter 1978).

The amounts of food provided daily by the 0.6 , 0.8 , and $1.0 \mathrm{ml} / \mathrm{h}$ feeders exceeded the estimated daily energy expenditures of $A$. alexandri (see Methods). It is possible that food availability was too high to detect some behavioral responses; for example, because food was not severely limiting in these experiments there was less need for $A$. alexandri to reduce energy expenditures than there was in the earlier study of $C$. anna (see Ewald and Carpenter 1978).

\section{Community structure of nectarivores}

Dominance status between species of nectarivores is generally positively related to body size and floral density (Stiles and Wolf 1970; Wolf 1970; Johnson and Hubbell 1975; Lyon 1976; Feinsinger 1976; Wolf et al. 1976; Carpenter 1978; Carpenter and MacMillen 1980). Calypte anna are larger than $A$. alexandri and tend to displace rather than be displaced by $A$. alexandri in aggressive interactions (see Introduction and Results). Yet, $A$. alexandri strongly defended $0.3 \mathrm{ml} / \mathrm{h}$ feeders in the presence of $C$. anna intruders.

Although body size may have a direct effect on the dominance relationships between $C$. anna and $A$. alexandri in fights over rich resources, our results suggest that interspecific asymmetries in energetic payoffs from territorial defense need to be considered.
Because the average daily energy requirements of $C$. anna are greater than those of $A$. alexandri, small amounts of food supply relatively less of the daily energy requirements of $C$. anna; $C$. anna should, therefore, defend poor territories less strongly than $A$. alexandri. The results support this contention: A. alexandri's defense of $0.3 \mathrm{ml} / \mathrm{h}$ territories was more vigorous than $C$. anna's (see Table 2) and $A$. alexandri's average net energy gain from their territories was estimated to be greater.

On poor territories (i.e., $0.3 \mathrm{ml} / \mathrm{h}$ ), intrusion rates were low and not perceptibly greater for $A$. alexandri than for $C$. anna (row 4, Table 2). The greater proportion of energy gained by $A$. alexan$d r i$ (relative to their requirements) therefore was not associated with a detectable increase in defense costs. The energetic payoff asymmetry should therefore favor $A$. alexandri over $C$. anna.

In contrast, when each species defended extremely rich territories, $A$. alexandri suffered greater intrusion pressure and spent more energy in defense than $C$. anna. When resources are rich, effects of body size on dominance should be of increased importance because adversaries may be more highly motivated to intrude to steal food from a territory or usurp a territory or a portion of it. In such situations increased threat of injury from owners may help deter intruders. Because larger owners probably impose a greater threat of injury, intruders should tend to avoid territories defended by $C$. anna relative to the smaller $A$. alexandri. This preferential avoidance may be amplified by the tendency for $C$. anna to monopolize territories in rich habitats $-A$. alexandri on rich patches may not be recognized so readily as owners and may therefore suffer greater intrusion pressure. Our data from unrestricted feeders suggest that the end result of these interactions is an overall energetic asymmetry (sensu Parker 1974; Ewald and Rohwer 1980; Ewald 1985) in favor of the larger species. That is, the net energy payoff from very rich territories is greater for $C$. anna than for A. alexandri.

During the experiments comparing the two species on rich and poor territories, the best alternative to territoriality was to intrude on ad lib territories. The dramatic difference between the results from rich and poor territories (Tables 2 and 3) and the limited alternatives to territoriality suggest that the differences between the species are not due to differences in the net gain from alternatives, but this possibility cannot be rigorously evaluated without measurement and experimental manipulation of the alternatives.

In a study of $A$. alexandri, energetic asymme- 
tries between adversaries was related to intraspecific dominance, but body size was not (Ewald 1985). Interspecifically, body size has been correlated with dominance (Wolf 1970; Feinsinger 1976; Lyon 1976; Wolf et al. 1976), but the role of energetic asymmetries between territorial species remains uncertain. The present study raises the possibility that energetic asymmetries may contribute to such interspecific dominance relationships.

The reversals of interspecific energetic asymmetries as a function of resource density is noteworthy because interspecific dominance relationships are often graded: members of the "subordinate" species will often defend poor territories in the presence of larger "dominant" species and sometimes displace members of the "dominant" species (Stiles 1973; Feinsinger 1976). In his documentation of $C$. anna's general monopolization of prime habitats when sympatric with Selasphorus sasin (Allen's hummingbird), Pitelka (1951) stated that S. sasin, which is about $25 \%$ smaller, is able to control portions of the habitat that seemed less favorable to $C$. anna. He concluded that the "details of success in competitive establishment of $S$. sasin males in these instances are unknown." A few years later, at a more southern study site (in Santa Cruz rather than Berkeley, California) male $S$. sasin tended to dominate male C. anna (Legg and Pitelka 1956). Our arguments relating productivity, body size and payoff asymmetries provide a readily testable explanation of these trends.

Stiles and Wolf (1970) proposed that interspecific territoriality might partition flowers according to nectar density. In their Central American system the largest species (Phaeochroa cuvierii) was about twice the size of the other primary species (Amazilia rutila and $A$. saucerrotii). Because $P$. cuvierii apparently intruded at will (Wolf 1970), Amazilia's territoriality in the presence of Phaeochroa, seemed to depend partly on a low population of the Phaeochroa (Stiles and Wolf 1970). Yet even in this system, energetic asymmetries may play some role in the aggressive partitioning of the resources; Phaeochroa was excluded by $A$. rutila in nearly $10 \%$ of encounters on one resource type (Stiles and Wolf 1970).

Pimm et al. (1985) experimentally demonstrated a relationship between $A$. alexandri and the larger blue-throated hummingbird (Lampornis clemenciae) that was similar to the interspecific relationship demonstrated in our study. Their use of unrestricted provisioning of food, however, would not tend to reveal energetic advantages that the smaller species might have over the larger species during territorial monopolization of poor food sources; consequently, although their model is consistent with our results, they emphasized community-level effects of the aggressive exclusion of the smaller species from the richest resources.

Potential sources of error (see Ewald 1985) and the artificiality of our experimental system must be borne in mind when evaluating our results. One potential problem concerns presentation of food on territories from a virtual point-source. The observed intraspecific and interspecific differences in territorial behavior might change as the spatial and temporal distributions of food changes. In this regard it is noteworthy that these same uncertainties were potentially applicable to the earliest experimental studies of territorial dynamics using feeders (Ewald and Carpenter 1978). Yet, (1) gradual changes in time invested on territories as a function of territory quality, (2) temporal relationships between foraging and territorial behaviour, and (3) the use of energetically expensive defense by nectarivores as a function of territory quality in natural situations have been shown to be similar to those in the artificial situations (see Introduction). Additional tests of our hypotheses about interspecific dominance relationships and energetic asymmetries using both natural and experimental systems should help clarify the general significance of our findings.

Acknowledgements. Financial support for this study was provided by a fellowship from the Michigan Society of Fellows and the following grants to P.W.E.: a Grant for Improving Doctoral Dissertations from the National Science Foundation (DEB7715521), two grants from the Harry Frank Guggenheim Foundation, and grants from the Chapman Fund of the American Museum of Natural History and the Orange County, California Chapter of the National Audubon Society. For access to study sites and use of facilities we thank J.D. Griffen, W.D. Koenig, and F.A. Pitelka (at Hastings Reservation); R. Munson and B. Thomas (at Tucker Wildlife Sanctuary); and J. Froke (at Starr Ranch Audubon Sanctuary). We thank P. Arcese, C.E. Bayer, C. Copenhaver, L. McKinney, M.E. Norton, D. Neustadt, and R.T. Ray for help in collecting and analyzing data; S. Bittenbender, C. Jaspersohn and N. Loescher for help in manuscript preparation; and F.L. Carpenter, P. Feinsinger, H. Markl, M.L. Rosenzweig, and L.L. Wolf for comments on the manuscript.

\section{References}

Armstrong DP (1987) Economics of breeding territoriality in male calliope hummingbirds. Auk (in press)

Carpenter FL (1978) A spectrum of nectar-eater communities. Am Zool 18:809-819

Carpenter FL, MacMillen RE (1980) Resource limitation, foraging strategies, and community structure in Hawaiian honeycreepers. Proceedings of the 17 th International Ornithological Congress 2:1100-1104

Epting RJ (1980) Functional dependence of the power for hovering on wing disc loading in hummingbirds. Phys Zool $53: 347-357$ 
Ewald PW (1985) Influences of asymmetries in resource quality and age on aggression and dominance in black-chinned hummingbirds. Anim Behav 33:705-719

Ewald PW, Carpenter FL (1978) Territorial responses to energy manipulations in the Anna Hummingbird. Oecologia (Ber(in) $31: 277-292$

Ewald PW, Rohwer S (1980) Age, coloration and dominance in non-breeding hummingbirds: a test of the asymmetry hypothesis. Behav Ecol Sociobiol 7:273-279

Ewald PW, Orians GH (1983) Effects of resource depression on use of inexpensive and escalated aggressive behavior: experimental tests using Anna hummingbirds. Behav Ecol Sociobiol 12:95-101

Feinsinger P (1976) Organization of a tropical guild of nectarivorous birds. Ecol Monogr 46:257-291

Frost SK, Frost PGH (1980) Territoriality and changes in resource use by sunbirds at Leonotis leonurus (Labiatae). Oecologia (Berlin) 45:109-116

Gass CL, Angehr G, Centa J (1976) Regulation of food supply by feeding territoriality in the rufous hummingbird. Can J Zool 54:2046-2054

Gass CL (1978) Rufous hummingbird feeding territoriality in a suboptimal habitat. Can J Zool 56:1535-1539

Gass CL, Montgomerie RD (1981) Hummingbird foraging behaviour: decision-making and energy regulation. In: Kamil AC, Sargent TD (eds) Foraging behaviour: ecological, ethological and psychological approaches. Garland STPM Press, New York, pp 159-194

Hainsworth FR (1974) Food quality and foraging efficiency of sugar assimilation by hummingbirds. J Comp Physiol $88: 425-431$

Johnson LK, Hubbell SP (1975) Contrasting foraging strategies and coexistence of 2 bee species on a single resource. Ecology $56: 1398-1406$

Lasiewski RC (1963) Oxygen consumption of torpid, resting, active, and flying hummingbirds. Physiol Zool 36:122-140

Legg K, Pitelka FA (1956) Ecologic overlap of Allen and Anna hummingbirds nesting at Santa Cruz, California. Condor $58: 393-405$
Lyon DL (1976) A montane hummingbird territorial system in Oaxaca, Mexico. Wils Bull 88:280-299

Maynard Smith J, Parker GA (1976) The logic of asymmetric contests. Anim Behav 24:159-175

Parker GA (1974) Assessment strategy and the evolution of fighting behaviour. J Theor Biol 47:223-243

Paton DC, Carpenter FL (1984) Peripheral foraging by territorial rufous hummingbirds: defense by exploitation. Ecology 65:1808-1819

Pimm SL, Rosenzweig ML, Mitchell W (1985) Competition and food selection: field tests of a theory. Ecology 66: 798-807

Pitelka FA (1951) Ecologic overlap and interspecific strife in breeding populations of Anna and Allen hummingbirds. Ecology 32:641-661

Powers DR (1987) Effects of variation in food quality on the breeding territoriality of the male Anna Hummingbird ( $\mathrm{Ca}$ lypte anna). Condor 89:103-111

Siegel S (1956) Nonparametric statistics for the behavioral sciences. McGraw-Hill Series in Psychology, New York, NY, USA

Sokal RR, Rohlf FJ (1981) Biometry. Freeman, San Francisco,

Stiles FG (1973) Food supply and the annual cycle of the Anna hummingbird. Univ Calif Publ Zool 97:1-109

Stiles FG, Wolf LL (1970) Hummingbird territoriality at a tropical flowering tree. Auk 87:467-491

Tamm S (1985) Energetically expensive displays by hummingbirds: A basis for mate choice? Behav Ecol Sociobiol 16:203-207

Wilhelm K, Comtesse H, Pflumm W (1980) Zur Abhängigkeit des Gesangs vom Nahrungsangebot beim Gelbbauch-Nektarvogel (Nectarinia venusta). Z Tierpsychol 54:185-202

Wolf LL (1970) The impact of seasonal flowering on the biology of some tropical hummingbirds. Condor 72:1-14

Wolf LL (1978) Aggressive social organization in nectarivorous birds. Am Zool 18:765-778

Wolf LL, Stiles FG, Hainsworth FR (1976) Ecological organization of a tropical, highland hummingbird community. $J$ Anim Ecol 45:349-379 